\title{
Mode of Infection with Larval Anisakid Nematodes in the Japanese Flying Squid, Todarodes Pacificus (Cephalopoda: Ommastrephidae)
}

\author{
Hideo TAKAHARA ${ }^{1,2^{*}}$, Rie GOTO ${ }^{3}$, Taiju SAITO ${ }^{3}$, Yasunori SAKURAI ${ }^{4}$ \\ ${ }^{1}$ Graduate School of Fisheries Sciences, Hokkaido University, Minato-cho, Hakodate, Hokkaido, Japan. \\ ${ }^{2}$ Present address : Fisheries and Oceans Hakodate, Benten-cho, Hakodate, Hokkaido, Japan. \\ ${ }^{3}$ South Ehime Fisheries Research Center, Ehime University, Ainan-cho Uchidomari, Minamiuwa-gun, Ehime, \\ Japan. \\ ${ }^{4}$ Hakodate Cephalopod Research Center, Fisheries and Oceans Hakodate, Benten-cho, Hakodate, Hokkaido, \\ Japan.
}

*Corresponding Author: Hideo TAKAHARA, Fisheries and Oceans Hakodate, Benten-cho, Hakodate, Hokkaido, Japan

\begin{abstract}
The Japanese flying squid, Todarodes pacificus, is generally infected by third-stage larvae of two species of anisakid nematodes. Anisakis sp. is typically observed encapsulated in the outer wall of the stomach and caecum of infected squids, whereas Lappetascaris sp. is found at the anterior end of the mantle musculature. To investigate the infection process, third-stage larvae of these two anisakid species were labelled by injecting a mixture of 5\% fluorescein isothiocyanate-dextran and 5\% biotin-dextran into their caudal end. The labelled larvae were placed inside the muscle tissue of dead prey fish which were then fed to freely swimming squids held within a large aquarium. Several days later, the squids were removed, killed and dissected to observe the characteristics of infection by fluorescing anisakids. Anisakis sp. larvae were found infecting the outer walls of the stomach and caecum, but no Lappetascaris infections were observed. Squids held inside custom-made plastic packs containing free anisakid larvae were not infected with Anisakis sp. but Lappetascaris sp. larvae were found attached to the gills. We conclude that Anisakis sp. penetrates the squid digestive tract after squids consume Anisakis-infested prey; while Lappetascaris sp. infects squids by direct entry through their gills following inhalation of ambient seawater.
\end{abstract}

Keywords: Anisakid nematodes, Todarodes pacificus, fluorescent labelling, FITC

\section{INTRODUCTION}

The larval stages of anisakid nematodes are the most common parasites of the Japanese flying squid, Todarodes pacificus. These nematodes include Anisakis simplex sensu lato (cf. 1,2), here referred to as Anisakis sp., and Lappetascaris sp., both at the third larval stage [3-5]. The larval stages of the life cycle of Anisakis sp. involve several hosts, including squid and fish. Adult parasites live in the guts of the definitive hosts, which typically are marine mammals, especially cetaceans [6-9]. The cycle begins when the definitive host releases the parasite eggs in their faeces. The eggs develop and hatch in the environment, releasing free-living third-stage larvae [10, 11]. Planktonic or semi-planktonic crustaceans are intermediate hosts, ingesting these larvae. Fish and squids act as paratenic hosts, acquiring larvae through the diet by preying upon infected crustaceans and/or other fish species. The definitive hosts of these parasites are cetaceans, in which two molts occur (third-stage to fourth-stage, then to adult) before sexual maturity and egg production [9, 12-15].

The life cycle of Lappetascaris sp. is largely unknown. The definitive host of this species is thought to be a predatory marine fish [3, 4], although the source of larvae found in these fish is unknown.

The larvae of Anisakis sp. commonly appear encapsulated in the outer walls of the stomach and caecum of squids, whereas those of Lappetascaris sp. are found in the anterior end of the mantle musculature [3-5].

The North Pacific krill species, Euphausia pacifica and E. similis, have been successfully infected experimentally by A. simplex larvae in the laboratory $[16,17]$. However, the infection process in squids is unknown. The present study aimed to determine the route of infection of captive squid, T. pacificus, 
with third-stage larvae of the two anisakids. For the purpose of observing the infection process in $T$. pacificus a new method of fluorescence labeling of anisakid larvae was devised.

\section{Materials AND MethodS}

\subsection{Collection of Larval Anisakid Nematodes}

Japanese flying squids, Todarodes pacificus (Steenstrup, 1880), were caught in set nets off the Pacific coast of southeast Hokkaido, Japan, in November, 2009, and October, 2010 and inspected for parasite infestation. Third-stage larvae of the parasitic nematode Anisakis simplex sensu lato [1,2], henceforth referred to as Anisakis sp., were obtained from the outer wall of the squid stomach and caecum. Thirdstage larvae of Lappetascaris sp. were obtained from the anterior end of the squid mantle musculature. Both were found in freshly caught squid and in squid purchased at a fish market in Hakodate, southern Hokkaido, Japan, in October, 2010.

A few larvae were fixed in $70 \%$ ethanol or 5\% formaldehyde and cleared (rendered transparent) using glycerol, enabling inspection of the internal organs of the larvae for identification. Anisakis sp. larvae can be identified based on the presence of a long ventriculus with an obliquely shaped posterior end, a short rectum, and a rounded tail; while Lappetascaris sp. larvae are distinguished by the presence of an elongate-oval ventriculus, a very long ventricular appendix, a conspicuous oesophageal gland, and a conical tail [3].

Living larvae of both species were removed and placed in Petri dishes filled with seawater, maintained at $8^{\circ} \mathrm{C}$ under a $12: 12$ circadian light regime. The water was changed every day. These larvae were checked daily for viability by reaction to gentle agitation with a needle and dead larvae were removed.

\subsection{Labeling of Larvae}

Living larvae were incubated at $8^{\circ} \mathrm{C}$ for three days then labelled [18] by injecting a mixture of $5 \%$ fluorescein isothiocyanate-dextran and 5\% biotin-dextran (FITC-biotin) in $0.2 \mathrm{M} \mathrm{KCl}$ into the caudal end of each larva and viewed using fluorescence microscopy (LEICA MZ16F, GFP2 filter set: excitation 480/40 nm; barrier $510 \mathrm{~nm}$ ). An Eppendorf microinjector was used to introduce the dye, with the larvae placed in a glass dish coated with $1 \%$ agar and filled with seawater. The quantity injected was just sufficient to coat the inside of the anisakid cuticle with FITC-biotin. Injected larvae of both species were returned to a new Petri dish filled with seawater at $8^{\circ} \mathrm{C}$.

\subsection{Feeding Experiments}

Live T. pacificus were caught using set nets in November 2009 and October 2010 in the waters off southern Hokkaido. The squid were maintained together in a 10,000-L aquarium, in which the water temperatures variation was $15-16^{\circ} \mathrm{C}$. In November 2009 , live $T$. pacificus were tagged on a fin using a plastic ribbon tag for individual identification. Tagging was performed under cold-water anesthesia (0$1^{\circ} \mathrm{C}$ seawater) [19]. Three to five FITC-labelled larvae of Anisakis sp. were placed in pieces of frozen fillets of Pacific saury (Cololabis saira), which were then fed to each of three squids for two days. In the same way, labelled larvae of Lappetascaris sp. were fed to eight different squids. Each squid received two or three infested fillets per day.

Any food that was not consumed was collected and the number of larvae remaining was counted. Experimentally infected squid were observed for 1 hour to ensure that larvae were not regurgitated. The aquarium was cleaned daily by siphon and inspected for expelled larvae until the end of the experiment. After 4-5 days of feeding on infested feed, all squid were netted, killed and examined for larval infection using fluorescent microscopy. All obtained larvae were fixed in $70 \%$ ethanol or 5\% formaldehyde and cleared using glycerol for microscopic observation.

In October, 2010, about six labelled larvae of Lappetascaris sp. were placed in each of a number of pieces of frozen saury fillet. Two or three pieces were fed to each of four tagged squids and 2 or 11 hours after feeding, the squids were collected and examined for larval infection.

\subsection{Exposure of Squid to Free-Swimming Larvae}

In November 2009, three individual live T. pacificus were placed individually with 13-20 labelled larvae of Anisakis sp. in separate 5-L transparent plastic transporter bag containing 1.5-2.5-L of seawater at 0$1{ }^{\circ} \mathrm{C}$ with approximately 2.5-3.5 1 of oxygen gas (custom-made plastic packs used for transporting live 
Mode of Infection with Larval Anisakid Nematodes in the Japanese Flying Squid, Todarodes Pacificus (Cephalopoda: Ommastrephidae)

squid [19]). Similarly, five live T. pacificus individuals and 20-30 labelled larvae of Lappetascaris sp. were placed in identical plastic transporter bags.

The bags were placed in an incubator $\left(8^{\circ} \mathrm{C}\right)$ for $1 \mathrm{~d}(12 \mathrm{~h}$ dark, $12 \mathrm{~h}$ light). The squids were then removed and examined for larval infection.

\section{Results}

All FITC-positive larvae were observed to be within the pseudocoelom, where they were easily recognized under the fluorescence microscope (Fig. 1). Lappetascaris sp. larvae showed active behavior even on an agar-coated dish, where they were observed to promptly burrow into the medium soon after being placed in the dish.

In feeding experiments, all squids consumed the fillets they were fed, and no larvae were regurgitated. Table 1 shows the results. Anisakis sp. larvae were found in each of the three squids tested. The larvae were encapsulated in the outer wall of the stomach or caecum, but no larvae were found in the mantle musculature or other internal organs. Fig. 2 shows a squid infected by Anisakis sp., where two larvae can be seen, one in the caecum and the other in the stomach. However, only the larva in the caecum was fluorescent, indicating that it was an experimental specimen; the one in the stomach was presumably from a natural infection when the squid was still in the wild. Interestingly, while no Lappetascaris sp. larvae were found in any of the squid 4-5 days after they had been fed with feed containing labelled larvae, another experiment revealed freely moving larvae in the squids 2 or 11 hours after feeding (Table 2), indicating that the squid did ingest these larvae in their food but did not suffer digestive tract infection by this species.

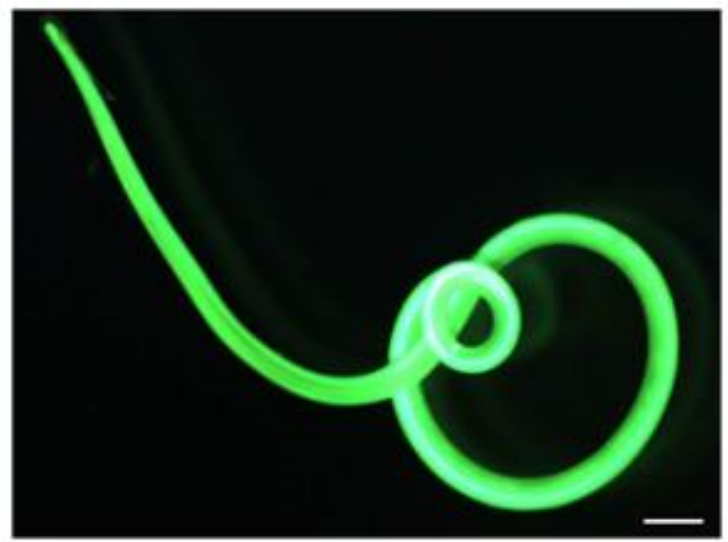

Fig1. Third-stage larva of Anisakis sp. labelled by injecting a 5\%FITC-biotin. Scale bar $1.0 \mathrm{~mm}$.

Table1. Infection of Todarodes pacificus by third-stage larvae of two species of anisakid nematodes labelled with $5 \%$ FITC-biotin and included in the diet

\begin{tabular}{|c|c|c|c|c|c|c|c|c|}
\hline & \multirow{2}{*}{$\begin{array}{c}\text { Mantle } \\
\text { length } \\
\text { of squid } \\
(\mathrm{mm})\end{array}$} & \multirow{2}{*}{$\begin{array}{c}\text { Body } \\
\text { weight } \\
\text { of squid } \\
\text { (g) }\end{array}$} & \multirow[b]{2}{*}{$\begin{array}{l}\text { No. of } \\
\text { larvae } \\
\text { given }\end{array}$} & \multirow[b]{2}{*}{$\begin{array}{l}\text { Day of } \\
\text { collection }\end{array}$} & \multicolumn{4}{|c|}{ Location of infection } \\
\hline & & & & & Stomach & Caecum & $\begin{array}{c}\text { Mantle } \\
\text { anterior } \\
\text { end }\end{array}$ & $\begin{array}{l}\text { Mantle } \\
\text { posterior } \\
\text { end }\end{array}$ \\
\hline \multirow[t]{3}{*}{ Anisakis sp. } & 234 & 256 & 8 & 4 & 1 & 0 & 0 & 0 \\
\hline & 250 & 334 & 11 & 5 & 0 & 1 & 0 & 0 \\
\hline & 236 & 238 & 16 & 5 & 0 & 1 & 0 & 0 \\
\hline \multirow[t]{8}{*}{ Lappetascaris sp. } & 245 & 269 & 5 & 4 & 0 & 0 & 0 & 0 \\
\hline & 258 & 318 & 5 & 4 & 0 & 0 & 0 & 0 \\
\hline & 240 & 293 & 5 & 4 & 0 & 0 & 0 & 0 \\
\hline & 243 & 304 & 5 & 4 & 0 & 0 & 0 & 0 \\
\hline & 225 & 221 & 7 & 4 & 0 & 0 & 0 & 0 \\
\hline & 230 & 223 & 12 & 4 & 0 & 0 & 0 & 0 \\
\hline & 251 & 276 & 14 & 4 & 0 & 0 & 0 & 0 \\
\hline & 241 & 270 & 10 & 5 & 0 & 0 & 0 & 0 \\
\hline
\end{tabular}



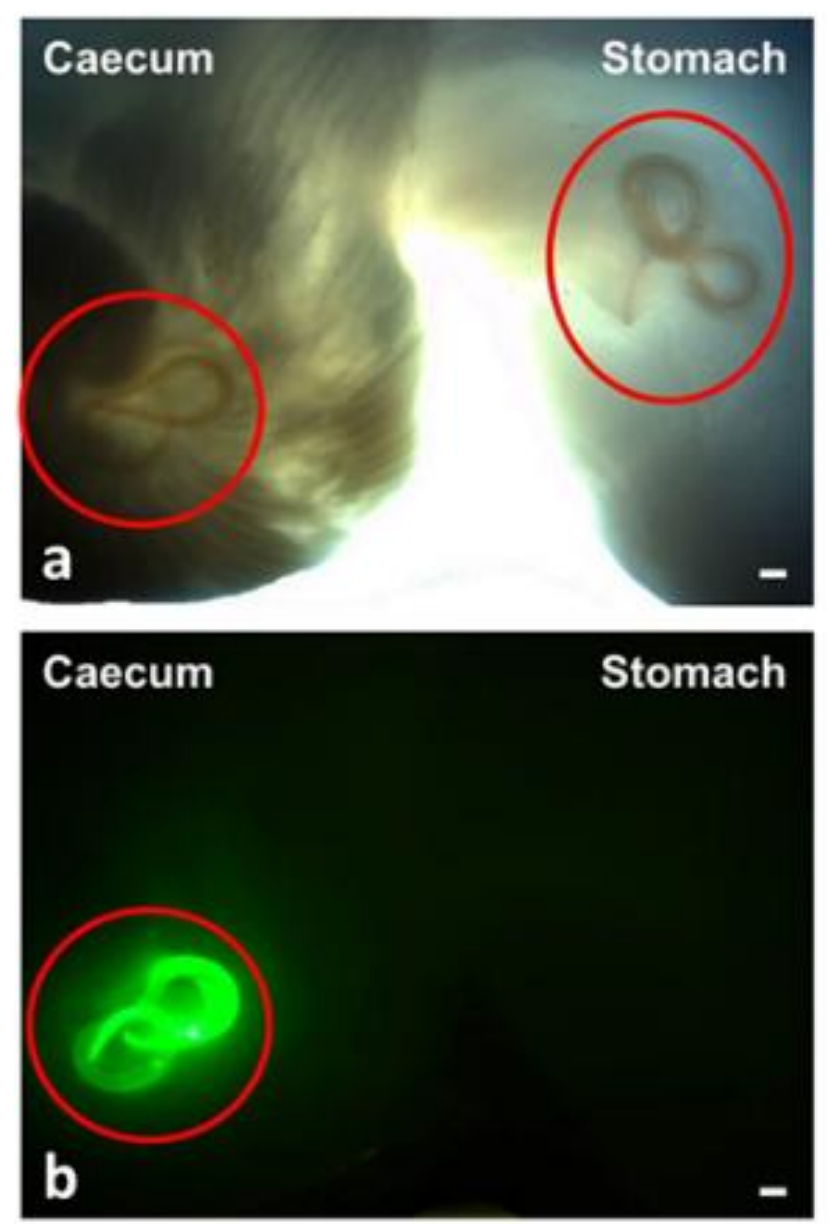

Fig2. Infection of squid by Anisakis sp. larvae after the feeding experiment.

(a) Viewed by conventional microscopy and normal light source. Two larvae can be seen encapsulated in the outer wall of the stomach and the caecum.

(b) Viewed by fluorescence microscopy. Note that only the larva in the caecum shows FITC-fluorescence, so it was introduced experimentally, while that in the stomach wall was presumably introduced naturally before the squid was captured. Scale bar $1.0 \mathrm{~mm}$.

Table2. Infection of T. pacificus by third-stage larvae of Lappetascaris sp. that were labelled with 5\% FITCbiotin and included in the diet

\begin{tabular}{|c|c|c|c|c|c|c|c|}
\hline \multirow{2}{*}{$\begin{array}{l}\text { Mantle } \\
\text { length } \\
\text { of squid } \\
(\mathrm{mm})\end{array}$} & \multirow{2}{*}{$\begin{array}{l}\text { Body } \\
\text { weight } \\
\text { of squid } \\
\text { (g) }\end{array}$} & \multirow{2}{*}{$\begin{array}{l}\text { No. of } \\
\text { larvae } \\
\text { given }\end{array}$} & \multirow{2}{*}{$\begin{array}{l}\text { Hour of } \\
\text { collection }\end{array}$} & \multicolumn{4}{|c|}{ Location of larvae in host } \\
\hline & & & & Stomach* & Caecum & $\begin{array}{c}\text { Mantle } \\
\text { anterior } \\
\text { end }\end{array}$ & $\begin{array}{c}\text { Mantle } \\
\text { posterior } \\
\text { end }\end{array}$ \\
\hline 209 & 174 & 5 & 2 & 1 & 0 & 0 & 0 \\
\hline 184 & 122 & 5 & 2 & 2 & 0 & 0 & 0 \\
\hline 192 & 133 & 6 & 11 & 6 & 0 & 0 & 0 \\
\hline 211 & 191 & 7 & 11 & 7 & 0 & 0 & 0 \\
\hline
\end{tabular}

Table 3 gives the results of the exposure experiment. No Anisakis sp. larvae were found in the internal organs or mantle musculature, although two larvae were found freely moving in the mantle cavity of two squids. In contrast, Lappetascaris sp. larvae were found attached to the gills of two of the five squids. These larvae remained active (Fig. 3). 
Mode of Infection with Larval Anisakid Nematodes in the Japanese Flying Squid, Todarodes Pacificus (Cephalopoda: Ommastrephidae)

Table3. Infection of T. pacificus by third-stage larvae of two species of anisakid nematodes that were labelled with 5\% FITC-biotin and introduced into the tank containing the squid.

\begin{tabular}{|c|c|c|c|c|c|c|}
\hline & \multirow{2}{*}{$\begin{array}{l}\text { Mantle } \\
\text { length } \\
\text { of squid } \\
\text { (mm) }\end{array}$} & \multirow{2}{*}{$\begin{array}{l}\text { body } \\
\text { weight } \\
\text { of squid } \\
\text { (g) }\end{array}$} & \multirow{2}{*}{$\begin{array}{c}\text { No. of } \\
\text { larvae } \\
\text { introduced }\end{array}$} & \multirow{2}{*}{$\begin{array}{l}\text { Hour of } \\
\text { collection }\end{array}$} & \multicolumn{2}{|c|}{ Location of larvae in host } \\
\hline & & & & & $\begin{array}{l}\text { Mantle } \\
\text { cavity }\end{array}$ & $\begin{array}{c}\text { Attached } \\
\text { to gill }\end{array}$ \\
\hline \multirow[t]{3}{*}{ Anisakis sp. } & 252 & 311 & 15 & 24 & 0 & 0 \\
\hline & 237 & 298 & 13 & 27 & 2 & 0 \\
\hline & 246 & 305 & 20 & 27 & 2 & 0 \\
\hline \multirow[t]{5}{*}{ Lappetascaris sp. } & 233 & 264 & 20 & 22 & 2 & 2 \\
\hline & 251 & 311 & 20 & 22 & 0 & 6 \\
\hline & 265 & 397 & 30 & 24 & 4 & 0 \\
\hline & 258 & 343 & 24 & 27 & 2 & 0 \\
\hline & 245 & 259 & 24 & 27 & 3 & 0 \\
\hline
\end{tabular}
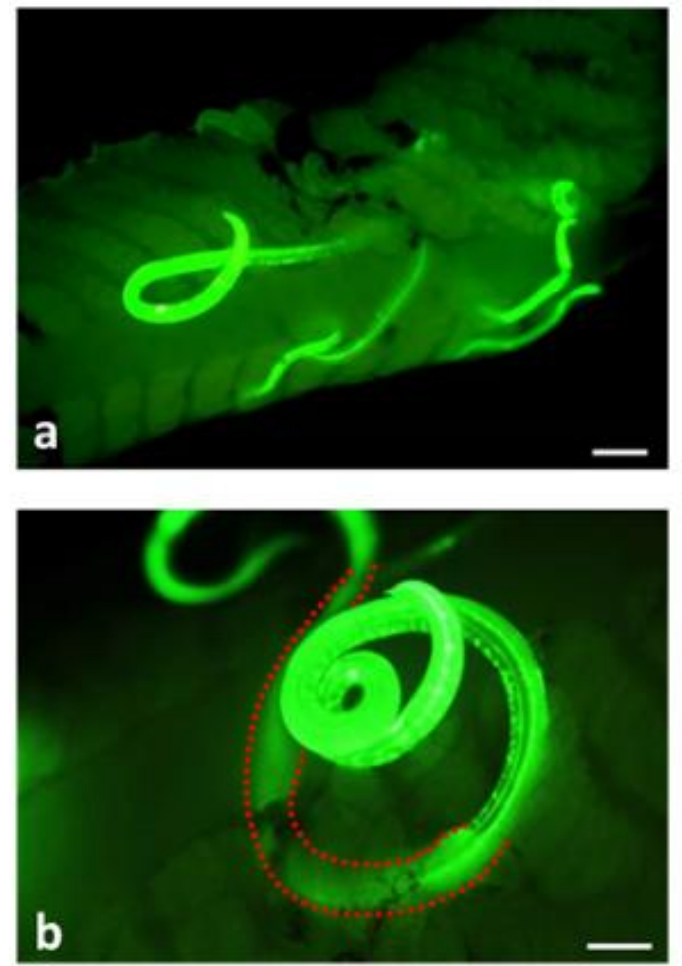

Fig3. Infection of squid by Lappetascaris sp. larvae after the exposure experiment.

(a) Fluorescent view of the gill of the infected squid. (b) Magnified image of (a). These infecting larvae have burrowed into the tissue. The dotted line represents the body of the larva within the gill. Scale bars $100 \mu \mathrm{m}$ in (a) and $50 \mu \mathrm{m}$ in (b).

\section{DISCUSSION}

The methodology proposed in the present study is clearly effective for investigating infection with anisakid larvae. It was found possible to culture the injected larvae outside of the hosts for up to three weeks, after which they died, most likely due to starvation. Furthermore, fluorescence microscopy demonstrated that all the larvae were successfully labelled, thus validating injection of 5\% FITC-biotin into the caudal end of larval anisakid nematodes as a good method for labelling nematodes. 
Experimental infection of squids with Anisakis sp. larvae embedded within feed items resulted in encapsulation of larvae in the outer wall of the squid stomach or caecum. Takahara and Sakurai [5] reported that T. pacificus are infected with Anisakis sp. in the Sea of Okhotsk and the Oyashio region off eastern Hokkaido, suggesting that T. pacificus is infected with third-stage larvae of Anisakis sp. indirectly through preying on infected crustaceans or fish (e.g., walleye pollock) in the Sea of Okhotsk and the Oyashio region. Although the larvae were directly fed to the squid in the present study, it is very likely that these larvae will go on to infest larger predators that prey upon infected crustaceans, squid and fish. Thus large predators may accumulate enormous numbers of larvae. These findings suggest that the life cycle of Anisakis sp. relies on the predator-prey relationships in the food web.

Although a few Lappetascaris sp. larvae were found inside the stomach of some squid, they did not infect the host in the feeding experiments reported here. This result strongly suggests that infection by Lappetascaris sp. larvae does not occur through the food web. Rather, as demonstrated in the exposure experiment, some larvae of Lappetascaris sp. present in the seawater are taken into the mantle cavity during swimming and ventillation of the gills, into which they apparently burrow. In contrast, although Anisakis sp. larvae were found freely moving within the mantle cavity, they were not observed to attach themselves to any tissues unless ingested. The larvae of Anisakis sp. develop to the third stage while still in the egg and are free-living upon hatching $[10,11]$. The life cycle of Lappetascaris sp. is largely unknown, although there appears to be a free-living period in its life cycle. In wild squid, the larvae are apparently found only in the anterior end of the mantle musculature [3-5]. Lappetascaris sp. larvae were observed to penetrate into the $1 \%$ agar plate during dye injection, while Anisakis sp. larvae did not show such behavior. From this result, we speculate that Lappetascaris sp. larvae may attach first to the gill, then burrow into the gill tissues before subsequently moving to the anterior end of the mantle musculature. Takahara and Sakurai [5] reported that Lappetascaris sp. in T. pacificus occurred on the coast off Hokkaido, suggesting that T. pacificus may become infected with third-stage larvae of Lappetascaris sp. directly by taking them into the mantle cavity with inhaled seawater during the migration of these squid around Hokkaido.

\section{CONCLUSION}

Recent studies have indicated that T. pacificus is infected by two anisakid nematodes, Anisakis sp. and Lappetascaris sp. We examined the route of infection for these two species in T. pacificus by means of experiments on captive squid, making use of a novel method of fluorescence labelling of the larvae. The results indicate that the third-stage larvae of Anisakis sp. infection happens indirectly following predation on infected euphausiids or fish; while infection with third-stage larvae of Lappetascaris sp. happens by direct exposure to larvae living free within the ambient seawater.

\section{ACKNOWLEDGMENT}

We thank fishmonger S. Tomita, his family at Hakodate City Free Market for providing squid containing larvae of anisakid nematodes, and K. Nagasawa, at Hiroshima University, for help with identifying the nematodes. We also thank E. Yamaha and K. Arai, at Hokkaido University, for providing the injection equipment.

\section{REFERENCES}

[1] Nascetti G., Paggi L., Orecchia P., Mattiucci S., Bullini L. (1983). Two sibling species within Anisakis simplex (Ascaridida: Anisakidae). Parassitologia., 25: 306-307.

[2] Simonetta M., Paolo C., Stephen C. W., Michela P., Federica M., Bruno B., David I. G., Giuseppe N. (2014). Genetic and morphological approaches distinguish the three sibling species of the Anisakis simplex species complex, with a species designation as Anisakis berlandi n. sp. for A. simplex sp. C (Nematoda: Anisakidae). J. Parasitol., 100 (2): 199-214.

[3] Nagasawa K., Moravec F. (1995). Larval anisakid nematodes of Japanese common squid (Todarodes pacificus) from the Sea of Japan. J. Parasitol., 81(1): 69-75.

[4] Nagasawa K., Moravec F. (2002). Larval anisakid nematodes from four species of squid (Cephalopoda: Teuthoidea) from the central and western North Pacific Ocean. J. Nat. Hist., 36: 883-891.

[5] Takahara H., Sakurai Y. (2010). Infection of the Japanese common squid, Todarodes pacificus (Cephalopoda: Ommastrephidae) by larval anisakid nematodes. Fish. Res., 106: 156-159.

[6] Shimazu T. (1974). Ecology. In: Nihon Suisan Gakkai., Eds. Fish and Anisakis, Koseisha Koseikaku, Tokyo, 23-43. 
[7] Smith J.W., Wootten R. (1978). Anisakis and Anisakiasis. Adv. Parasitol., 16: 93-163.

[8] Smith J.W. (1983). Anisakis simplex (Rudolphi, 1809, det. Krabbe, 1878) (Nematoda: Ascaridoidea): Morphology and morphometry of larvae from euphausiids and fish, and a review of the life-history and ecology. J. Helminthol., 54: 205-224.

[9] Nagasawa K. (1990). The life cycle of Anisakis simplex: A review. In: Ishikura H., Kikuchi K., Eds. Intestinal Anisakiasis in Japan: Infected Fish, Sero-Immunological Diagnosis, and Prevention, SpringerVerlag, Tokyo, 31-40.

[10] Køie M., Berland B., Burt D.B. (1995). Development to third-stage larvae occurs in the eggs of Anisakis simplex and Pseudoterranova decipiens (Nematoda, Ascaridoidea, Anisakidae). Can. J. Fish. Auat. Sci., 52(1): 134-139.

[11] Kikuchi S. (1997). Transformation of larvae in the eggs of Anisakis simplex during development. Parasitol. Int., 46 (Suppl.): 81.

[12] Sakanari J.A., McKerrow J.H. (1989). Anisakiasis. Clinical Microbiology Reviews, 278-284.

[13] Køie M., Fagerholm H.P. (1993). Third-stage larvae emerge from eggs of Contracaecum osculatum (Nematoda, Anisakidae). J. Parasitol., 79: 777-780.

[14] Nagasawa K. (1993). Review of human pathogenic parasites in the Japanese Common Squid (Todarodes pacificus). In: Okutani T., O'dor R.K., Kubodera T., Eds. Proceedings of the International Symposium on Cephalopod Fisheries Biology, Tokai University, Tokyo, 293-312.

[15] Hays R., Measures L.N., Huot J. (1998). Euphausiids as intermediate hosts of Anisakis simplex in the St. Lawrence estuary. Can. j. zool., 76: 1226-1235.

[16] Oshima T., Kobayashi A., Kumada M., Koyama T., Kagei N., Nemoto T. (1968). Experimental infection with second stage larva of Anisakis sp. on Euphausia similes and Euphausia pacifica. Jpn .J .Parasitol., 17: 585.

[17] Oshima T. (1972). Anisakis and anisakiasis in Japan and adjacent area. In: Morishita K., Komiya Y., Matsubayashi H., Eds. Progress of medical parasitology in Japan 4, Meguro Parasitological Museum, Tokyo, 305-393.

[18] Goto R., Saito T., Matsubara T., Yamaha E. (2019). Microinjection of Marine Fish Eggs. In: Liu C., Du Y., Eds. Microinjection: Methods and Protocols, Methods in molecular biology, Humana Press, New York, 475-487.

[19] Bower J.R., Sakurai Y., Yamamoto J., Ishii H. (1999). Transport of the ommastrephid squid Todarodes pacificus under cold-water anesthesia. Aquacult., 170: 127-130.

Citation: Hideo TAKAHARA, et.al, "Mode of Infection with Larval Anisakid Nematodes in the Japanese Flying Squid, Todarodes Pacificus (Cephalopoda: Ommastrephidae)”, International Journal of Innovative Studies in Aquatic Biology and Fisheries, 6(3), pp. 16-22. DOI: https:// doi.org/10.20431/2454-7670.0603003

Copyright: (C) 2020 Authors, this is an open-access article distributed under the terms of the Creative Commons Attribution License, which permits unrestricted use, distribution, and reproduction in any medium, provided the original author and source are credited. 